\title{
Development Moodle Customization Guidelines and Supporting Tools
}

\author{
Jeong Ah $\mathrm{Kim}^{\dagger}$. Sun Kyoon Park ${ }^{\dagger+}$
}

\begin{abstract}
Open Source Softwares(OSS) are increasingly deployed in several domains, many educational organization have tried to deploy the OSS LMS(Learning Management System). For deploying OSS LMS, customization for specific environment is critical requirement. In this paper, we implemented the supporting environment to integrate the Moodle and school information system for user and course management. It is the most important customization requirement for introducing the Moodle to school. Also, we implemented supporting environment for the most important requirement so that we verified the usability of our guideline. We applied our environment to verify the efficiency of customization process.
\end{abstract}

Keywords : Moodle, Learning Management, Open Source Softwares, Customization

\section{무들 커스터마이제이션 체계화 및 지원 도구 구현}

\author{
김 정 아 $^{+} \cdot$ 박 선 균 ${ }^{++}$
}

\begin{abstract}
요 약
공개소프트웨어는 많은 분야에 걸쳐 활용률이 점차 높아지고 있으며, LMS 분야에서도 공개소프트웨어의 활용이 점차 늘고 있다. 단, 공개 소프트웨어 LMS를 도입하려면, 기관별 특화 요구사항에 맞추어 연동 과정이 필수적이다. 본 연구에서는 공개소프트웨어 LMS인 무들을 학교 에 도입함에 있어 무들과 학사 시스템 간의 사용자 관리와 강좌 관리를 위한 연동 지원 도구를 구현하였고, 무들과 학사 시스템과의 연동 사례 를 통해 사용자 및 강좌 정보 연동을 효율적으로 수행하였다.
\end{abstract}

키워드 : 무들, LMS, 공개 소프트웨어, 커스터마이제이션

\section{1. 서 론}

공개소프트웨어란 어느 누구나 해당 소프트웨어를 자유롭 게 사용할 수 있는 소프트웨어로서, 원시프로그램(source program)이 공개되어 있다. 공개소프트웨어는 세계의 모든 개발자들이 자발적으로 개발에 참여할 수 있는 특징을 갖는 다. 최근 공개소프트웨어는 소프트웨어시장의 독점화를 방 지하고 기존 소프트웨어 산업에 대체재 형태의 다양한 제품 을 사용할 수 있기에 각 분야에 활발히 사용되고 있다[1]. 공개소프트웨어는 OS(Operating System), CRM(Customer Relationship Management), BPM(Business Process Management), LMS(Learning Management System) 등 다

\footnotetext{
※ 본 과제는 정보통신산업진훙원의 $\mathrm{SW}$ 공학 요소기술 개발과 전문인력 양성 사업의 결과물임.

† 정 회 원: 관동대학교 컴퓨터교육과 교수

+十 준 회 원 : 인천과학고등학교 교사

논문접수: 2012년 9월 5일

수 정 일 : 1차 2012년 9월 19일, 2차 2012년 9월 21일

심사완료 : 2012년 9월 21일

* Corresponding Author: JeongAh Kim(clara@kd.ac.kr)
}

양한 분야에서 활용할 수 있는 범용 애플리케이션들이 많이 있다[2].

이러닝(e-learning)의 보급 확대와 유러닝(u-learning)의 등장으로 인해 학습 관리 시스템(Learning Management System, 이하 LMS) 활용이 증가하고 있다[3]. 학교들은 기 관에 맞춘 시스템을 확보하기 위하여 고가인 상용 $\mathrm{LMS}$ 를 도입한 후 수정하거나, 정보 시스템 구축 프로젝트를 발주 한다. 그러나 지속적으로 발전하는 이러닝 및 유러닝 개념 과 새로운 정보 기술을 $\mathrm{LMS}$ 에 반영하기 위해 지속적으로 많은 비용을 투자하는 것은 학교에 부담스러운 일이다[4]. 공개소프트웨어 $\mathrm{LMS}$ 의 도입은 비용을 절감하면서 검증된 최신 개념을 반영할 수 있는 방법이다[5]. 공개소프트웨어 LMS로는 ILIAS, ATutor, .LRN, Sakai, Moodle 등이 있다 [6]. 이들 공개소프트웨어 $\mathrm{LMS}$ 들은 온라인 학습에 필요한 다양한 기능을 제공할 뿐 만 아니라 코드를 제공하고 있기 때문에 기관별 요구사항을 반영하여 수정이 가능하다[7].

공개 소프트웨어 $\mathrm{LMS}$ 중 가장 대표적으로 많이 사용하 는 것은 무들(Moodle)이다[4,5,8]. 무들 역시 다른 공개 소프 트웨어 LMS와 동일게 도입비용을 절감할 수 있고, 코드가 
공개되어 있기에 원하는 대로 수정이 가능하다는 이점이 있 다[9]. 또한, 무들 내에서도 다양한 학습 자원들이 있으며 플 러그인(plug-in)이나 필터(filter)를 사용하여 더 많은 기능들 을 추가할 수 있다. 무들은 지속적으로 빠르게 업데이트가 되면서 안정적인 지원을 하고 있다.

그럼에도 무들을 각 기관에서 도입함에 있어, 기존 시스 템과 연동이 필요하다. 무들과의 연동은 무들을 효율적으로 사용하기 위해서 기존 시스템에 등록되어 있는 사용자 정보 와 강좌 정보를 무들과 연동하여 사용자 관리와 강좌 관리 를 수행하기 위함이다. 또한 각 학교별 특화 요구사항이나 학교 사용자들의 역량에 따라서 무들이 제공하는 기능 중 활용 가능한 기능을 취사선택 하는 등의 커스터마이제이션 과정이 필수적이다.

무들은 잘 정의한 인터페이스와 기능 확장 기반을 제공하 고 있지만, 이를 설명하고 있는 산출물이 부족하고 명확한 개발 지침을 제공하지 않는다. 이는 공개 소프트웨어가 갖 는 제약점이기도 하다. 본 논문에서는 무들을 교육현장에 도입하기 위해서 필요한 공통의 요구사항을 도출하여 이를 지원하는 환경을 구현하고, 이 과정에서 무들 기능 확장에 필요한 개발 절차를 정형화 하였다.

본 논문의 결과를 통해 학교별 공통 요구사항을 구현한 연동 환경을 쉽게 재사용할 수 있을 뿐 아니라, 개발 지침 을 통해 무들이 제공하는 다양한 재사용 모듈을 기반으로 학교별 특화 기능 구현에 참조할 기반을 확보하였다.

2장에서는 $\mathrm{LMS}$ 의 일반적 개념과 무들을 논문에서 대상 $\mathrm{LMS}$ 로 선택한 배경을 설명한다. 3장에서는 무들 활용을 위 한 학교별 공통 커스터마이제이션 요구사항인 학사연동을 처리하기 위한 방법을 정의한다. 4장은 학사연동을 위한 환 경 구현 내용과 구현 과정에서 수립한 무들 확장 모듈 개발 절차를 정의한다. 5 장에서는 개발한 환경과 지침을 적용한 사례를 제시하여 실무 현장에서 활용 가능함을 보이고 6장 에서 결론을 맺는다.

\section{2. 학습관리 시스템}

\section{1 학습관리 시스템의 동향}

$\mathrm{LMS}$ 는 온라인을 통해 학생들의 성적과 학습 과정을 추 적하는 학습 이력 관리는 물론 수업의 출결 확인 등 학사운 영에 필요한 전반적인 사항들을 관리해 주는 시스템이다. 또한, $\mathrm{LMS}$ 는 학습에 필요한 컨텐츠의 개발과 평가, 관리에 이르기까지 교수-학습의 전반적 과정을 통합적으로 운영하 고 관리할 수 있는 시스템이다[10].

이러닝이 활성화 되면서 $\mathrm{LMS}$ 의 중요성이 부각되어 제공 기능이 확대되고 활용 범위가 넓어지고 있다. 초기 $\mathrm{LMS}$ 는 단순하게 칠판형 컨텐츠나 $\mathrm{VOD}$ (Video On Demand) 컨텐 츠, 단순 HTML(Hypertext Mark-up Language) 컨텐츠를 지원하는 수준이었다. 하지만 변하는 학습 환경과 다양한 학습내용을 수용하여 보다 높은 학습 효과를 얻으려면 $\mathrm{LMS}$ 의 학습 관리 및 지원 기능 강화가 필요하다[11]. LMS
의 기능이 고도화될수록 학생의 개별학습을 위한 맞춤형 학 습 환경을 효과적으로 구성할 수 있기 때문이다.

현재 국내에서 개발한 LMS는 학습자의 기록정보와 학습 관리, 그리고 학습내용 전달 기능을 포함하고 있으며, 역량 과 학습기술 관리기능, 학습기술 차이분석 기능, 학습객체 관리 기능과 상담시스템, LCMS(Learning Content Manage ment System), 학력진단 시스템, 커뮤니티 시스템과 같은 기타 학습도구와의 연결 기능도 제공하고 있다. 최근에는 학습관리 및 기타 기능들을 컴포넌트화 하여 서비스 형태에 따라 능동적으로 대체할 수 있는 솔루션의 형태로 진화하고 있으며, KMS(Knowledge Management System), 그룹웨어, 협업 솔루션과의 연계성을 강화하는 형태로 발전되어 가고 있다[12]. 국외의 LMS 동향으로 상용 LMS에는 Blackboard 와 $\mathrm{WebCT}$ 가 있고, 자발적 참여자로 구성된 공개소프트웨 어 $\mathrm{LMS}$ 가 개발되어 보급 확산 중이다.

\section{2 공개소프트웨어 LMS의 특징}

공개소프트웨어 LMS는 불특정 다수에게 프로그램 코드 를 공개하여, 자유롭게 사용, 수정 및 재배포가 가능한 오픈 소스 사상을 바탕으로 한 학습관리 시스템이다. 공개소프트 웨어 LMS는 여러 가지 장점이 있다[12].

첫째, 공개소프트웨어 $\mathrm{LMS}$ 는 상용 $\mathrm{LMS}$ 에 비해 사용자 중심의 활용이 가능하다는 점이다. 상용 $\mathrm{LMS}$ 는 개발자의 기술 및 경험적 요소에 의해 개발자 관점으로 개발하는 경 우가 많다. 이로 인해 학습자에 대한 고려가 상대적으로 적 어, 학습자들은 복잡한 기술적 요소를 활용하지 못하는 경 우가 많다. 그러나 공개소프트웨어 $\mathrm{LMS}$ 는 직접적 기술의 수혜자인 학습자가 직접 시스템에 구성에 참여하기 때문에 학습자 중심의 실용적인 도구를 만들어 낸다.

둘째, 공개소프트웨어 $\mathrm{LMS}$ 는 기술적 유연성이 높아 교육 대상이나 교육내용에 따라 변경이 용이하다. 더불어 교육환 경에 따라 자유롭게 변경 가능하기 때문에 기존 시스템에서 의 우수한 콘텐츠와 결합할 경우 큰 시너지 효과를 가져 올 수 있다.

셋째, 공개소프트웨어 $\mathrm{LMS}$ 는 가격적인 측면에서 장점을 가지고 있다. 그 예로 MIT sloan 경영대학원에서는 공개소 프트웨어 LMS의 하나인 닷런(.LRN)을 활용하였는데, 상용 LMS보다 25\%밖에 안되는 비용으로 운영하고 있다[13]. 투 자비용을 부담스러워하는 사용자들에게 활용 기회를 제공할 수 있다.

넷째, 상업적으로 개발되어 구입한 소프트웨어는 운영상 의 문제가 발견되어도 수정이 불가능하지만 공개소프트웨어 는 프로그램 코드를 사용자들에게 공개하기 때문에, 사용자 들이 문제를 발견하면 사용자들이 직접 문제에 대해 해결이 가능하다.

다섯째, 오픈 소스 커뮤니티 내에서 모든 정보가 상호 공유되기 때문에 상업화된 소프트웨어가 업그레이드되는 것 보다 훨씬 빠른 속도로 업그레이드되어 지며, 지속적 으로 더 편리한 기능을 갖춘 프로그램으로 발전시켜 나 간다[14] 
Table 1. Features of Open Source LMS

\begin{tabular}{|c|c|c|c|c|c|}
\hline 특징 & Moodle & ATutor & ILIAS & LRN & Sakai \\
\hline 시초 & $\begin{array}{c}\text { 2002년 } \\
\text { 오스트레일리아 }\end{array}$ & $\begin{array}{c}\text { 2002년 } \\
\text { 캐나다 토론도대학 }\end{array}$ & $\begin{array}{c}\text { 1997년 } \\
\text { 독일 퀼튼대학 }\end{array}$ & $\begin{array}{c}\text { 2003년 } \\
\text { 미국 MIT대학 }\end{array}$ & $\begin{array}{c}\text { 2004년 } \\
\text { 미국 미시건대학 }\end{array}$ \\
\hline $\begin{array}{l}\text { 라이 } \\
\text { 센스 }\end{array}$ & GNU GPL & GNU GPL & GNU GPL & GNU GPL & Sakai 라이센스 \\
\hline $\begin{array}{l}\text { 기술적 } \\
\text { 특징 }\end{array}$ & $\begin{array}{l}\cdot \text { SCORM 표준 } \\
\cdot \mathrm{PHP} \text { 언어로 기능 } \\
\text { 확장 가능 }\end{array}$ & $\begin{array}{l}\text { · IMS / SCORM 표준 } \\
\text { · HTTP Webserver 필요 }\end{array}$ & $\cdot$ SCORM, AICC & $\begin{array}{l}\text { · IMS / SCORM 표준 } \\
\text { - OpenACS }\end{array}$ & $\begin{array}{l}\text { · IMS표준 } \\
\text { · 표준지원에서 약함 }\end{array}$ \\
\hline $\begin{array}{l}\text { 교육적 } \\
\text { 특성 }\end{array}$ & $\begin{array}{l}\text { · 구성주의적 협동 } \\
\text { 학습에 초점 }\end{array}$ & $\begin{array}{l}\text { 학습스타일 및 개별화 } \\
\text { 학습 초점 }\end{array}$ & $\begin{array}{l}\text { 구성주의적 학습 } \\
\text { 지원 }\end{array}$ & $\begin{array}{l}\text { ·학교교육 및 기업 } \\
\text { 교육에서의 장점 } \\
\text { · 평가기능이 다소 약함 }\end{array}$ & $\begin{array}{l}\text { - 연구 기능을 가진 } \\
\text { 고등용 LMS }\end{array}$ \\
\hline 기타 특징 & $\begin{array}{l}\text { 상용 Blackboard } \\
\text { 다음으로 많이 } \\
\text { 사용 }\end{array}$ & $\begin{array}{l}\text { - 대학 및 기업에서 재정과 } \\
\text { 코드 지원 }\end{array}$ & $\begin{array}{l}\text { - 국제 ILIAS대회 } \\
\text { 개최 } \\
\text { - 대학 및 재단의 } \\
\text { 컨소시엄을 형성 }\end{array}$ & $\begin{array}{l}\text { · 강력한 프레임워크를 } \\
\text { 갖춰 새로운 모듈 추가 } \\
\text { 개발 }\end{array}$ & - 기업들의 든든한 후원 \\
\hline
\end{tabular}

\section{3 공개소프트웨어 LMS의 동향}

현재 약 200 여 개국의 50 여개의 공개소프트웨어 LMS가 존재한다. 이 가운데는 기존의 이러닝 시장을 위협하고 있 을 정도로 크게 성장한 것들이 있다. 그 중 좋은 평가와 많 은 관심을 받고 있는 것으로는 ILIAS, ATutor, .LRN, Sakai, Moodle 등이 있다[6]. Table 1은 공개소프트웨어 LMS 각각의 특징에 대한 비교이다[15].

LMS 별 주요한 특징들을 살펴보면 .LRN은 MIT와 하이 델베르그 대학에서 지속적인 개발을 통해 높은 안정성과 다 양한 기능을 갖춤으로써 기업수준에서 가장 많이 사용되는 $\mathrm{LMS}$ 이다. Sakai는 비교적 최신의 것으로 많은 기관과 학교 의 지원을 받으며 매우 활발히 연구 중인 프로젝트로서 향 후 발전에 있어 매우 기대되는 LMS이다. 마지막으로 무들 은 현재 최고의 LMS 중 하나로서 상용 LMS 시장과 견주 어 그 사용자나 규모면에서도 그 가치가 매우 크다고 할 수 있다[13].

\section{4 공개소프트웨어 LMS 무들}

무들(Moodle: Modular Object Oriented Dynamic Learning Environment)은 모듈형 객체 지향적이고 동적인 학습 환경을 만들어주는 $\mathrm{LMS}$ 로 양질의 온라인 강의를 제 공하고자 하는 교사들을 위해 개발된 강의 및 학습 관리 시 스템이다. 무들은 다른 시스템에 비해 사회적 구성주의 학 습 이론에 기반을 두고 다양한 학습 활동을 제공하고 있으 며, 사용자 편의성과 유연성을 극대화한 모듈화 구조이다. 보안과 관리 도구가 강력하며 IMS/SCORM(Instructional Management System / Sharable Content Object Reference Model) 표준을 지원하고 있다[17,18]. 무들은 협력학습을 효 과적으로 활용할 수 있도록 지원하는 학습자 중심의 강좌 관리 시스템으로써 교수자는 양질의 온라인 강좌를 쉽게 생 성하고 사용할 수 있다. 또한 설치 및 유지보수가 용이하며 빠른 업데이트를 지원하고 위키 시스템, 컨텐츠 관리 시스
템, SNS(Social Networking System) 등과 같은 다양한 환 경과 연동을 지원한다는 장점을 가지기 때문에 현재 수많은 학교와 훈련기관에서 사용하고 있다[7,18].

학교에서 무들을 활용하기 위해서는 필수적으로 학교에서 운영하는 학사시스템과 연동이 필요하다. 연동을 위해서는 여러 데이터베이스 테이블을 이해해야 하고, 관련 무들 모 듈을 수정해야 한다. 그러나 무들은 공개 소프트웨어로 코 드를 공개하고 있지만, 개발자들이 참조할 문서를 제공하고 있지 못하다. 각 학교별로 무들을 활용하려면 학사연동을 위한 추가 개발 절차를 밟아야 하고 이를 위해서 개발자들 은 무들 코드를 분석하는 활동을 매번 수행해야 한다.

\section{3. 무들과 학사 연동}

공개소프트웨어 $\mathrm{LMS}$ 를 도입하려면 학교 특성과 교과 운영 방식 및 학습자의 특성에 맞도록 인터페이스 및 학 습관리기능을 커스터마이케이션 할 필요가 있다. 본 논문 에서는 대표적인 커스터마이제이션 대상인 연동에 대한 요구사항을 식별하고, 무들과 학사 시스템간의 연동 방법 을 정의하여, 각 학교별 활용에 참조할 수 있는 모델을 제공하였다.

\section{1 연동 요구사항}

무들과 학사 시스템간의 연동 요구사항에는 사용자 관리 및 강좌 관리가 필요하다.

\section{1) 사용자 관리}

무들 사용자 역할로는 관리자, 강좌 생성자, 교수자, 보조 교수자, 학생 등이 있고, 무들을 사용하기 위해서는 우선적 으로 사용자가 등록되어 있어야 한다. 그러나 교수자와 학 생들에게 무들 회원으로 가입하게 하거나 관리자가 교수자 와 학생들을 개별로 등록하는 것은 비효율적이다. 학교의 
학사 시스템에 교수자와 학생들의 정보가 미리 등록되어 있 으므로 필요한 필수 정보들만 가져와 무들 사용자로 일괄 등록할 필요가 있다.

\section{2) 강좌 관리}

강좌 관리를 위해 무들은 강좌 등록, 강좌 내 교수자 및 학생 등록 등의 다양한 기능들을 제공한다. 이 중 강좌 운영 에 필수적인 강좌 생성과 강좌별 수강생 및 교수자를 등록하 는 과정을 관리자가 수작업으로 진행하는 것은 비효율적이 다. 학사 시스템에 미리 등록되어 있는 강좌와 담당 교수자, 수강 신청한 학생들의 필수 정보들, 강좌의 강의계획서만 가 져와 무들에 강좌를 일괄적으로 등록하는 것이 바람직하다.

\section{2 무들 지원 연동 방법}

1) 데이터베이스 수정을 통한 연동 방법

무들과 학사 시스템간 연동하는 방법으로는 데이터베이스 수정을 통한 방법이 있다. 무들의 데이터베이스 테이블은 대략 200개 정도가 있고, 데이터베이스 테이블간 서로 복잡 한 관계를 가지고 있다. 이들 테이블에 필요한 데이터를 저 장함으로써 무들을 기관용으로 바꿀 수 있다. 무들은 데이 터베이스 테이블간의 ER(Entity Relationship) 다이어그램을 제공하고 있으나 주요 몇몇 테이블에 불과하다. $\mathrm{ER}$ 다이어 그램을 제공하지 않는 요소들을 수정하려면 데이터베이스 스키마를 분석하고 이해한다는 문제점이 있다. 본 논문에서 는 학사연동 요구사항을 수용하는데 필요한 무들 데이터베 이스 주요 테이블을 Table 2와 같이 제시하였다.

Table 2. Essential Table of MOODLE Database

\begin{tabular}{|c|c|}
\hline 테이블명 & 설명 \\
\hline config & 환경설정 \\
\hline user & \multirow{2}{*}{ 사용자 정보 관리 } \\
\hline user_preferences & \\
\hline groups & \multirow{2}{*}{ 사용자 그룹 관리 } \\
\hline groups_members & \\
\hline role & 사용자 역할 관리 \\
\hline role_assignments & 강좌에서 사용자의 역할 관리 \\
\hline course & 강좌 관리 \\
\hline course_categories & 범주 관리 \\
\hline capabilites & 사용자 권한 등 무들의 여러 가지 권한 \\
\hline context & $\begin{array}{c}\text { 강좌, 사용자, 플러그인 등 모듈과 } \\
\text { 인스턴스간의 경로 관리 }\end{array}$ \\
\hline modules & 모듈 관리 \\
\hline block & 블록 관리 \\
\hline $\log$ & \multirow{2}{*}{ 로그 관리 } \\
\hline log_display & \\
\hline backup_config & \multirow{4}{*}{ 백업 및 복구 관리 } \\
\hline backup_courses & \\
\hline backup_files & \\
\hline backup_log & \\
\hline
\end{tabular}

2) 사용자 데이터 연동 방법

무들과 기존 학사 시스템간 사용자 데이터를 연동하기 위 해서 기존 학사 시스템의 사용자 데이터를 무들로 이관해야 한다. 무들 데이터베이스에서 사용자 관리에 필요한 테이블 의 정보는 Table 3 과 같다.

Table 3. Table for User Management

\begin{tabular}{|c|c|}
\hline 테이블명 & 설명 \\
\hline user & 사용자 정보 관리 \\
\hline user_preferences & 사용자에 대한 환경설정 관리 \\
\hline centext & 무들 시스템에서 사용자에 대한 경로 관리 \\
\hline
\end{tabular}

사용자 데이터 관리에 필요한 무들 데이터베이스를 이용 하여 기존 학사 시스템에서 무들로 사용자에 대한 데이터를 이관하는 절차를 Table 4와 같이 수립하였다.

Table 4. Procedure for User data migration

\begin{tabular}{|c|c|c|c|}
\hline 번호 & 활동 & 수행 작업 & 참조 \\
\hline 1 & $\begin{array}{c}\text { user 테이블 } \\
\text { 속성 변경 }\end{array}$ & $\begin{array}{l}\text { - user 테이블의 애트리뷰트 } \\
\text { 기본값(default) 속성 값을 } \\
\text { 변경한다. }\end{array}$ & $\begin{array}{c}\text { Table } \\
5\end{array}$ \\
\hline 2 & $\begin{array}{c}\text { 학사 } \\
\text { 시스템에서 } \\
\text { 데이터 추출 }\end{array}$ & $\begin{array}{l}\text { - 사용자 정보로 필요한 } \\
\text { 항목인 아이디, 비밀번호, } \\
\text { 이름, 이메일 주소 등의 } \\
\text { 데이터를 가져온다. }\end{array}$ & \\
\hline 3 & $\begin{array}{c}\text { 사용자 } \\
\text { 정보를 무들 } \\
\text { user } \\
\text { 테이블에 } \\
\text { 입력을 위한 } \\
\text { 데이터로 } \\
\text { 변환 }\end{array}$ & $\begin{array}{l}\text { · 학사 시스템에서 가져온 } \\
\text { 이름을 성과 이름으로 } \\
\text { 나눠서 입력한다. }\end{array}$ & \\
\hline 4 & $\begin{array}{c}\text { 무들에 } \\
\text { 사용자 } \\
\text { 데이터 입력 }\end{array}$ & $\begin{array}{l}\text { - 사용자 등록에 필요한 최소 } \\
\text { 항목인 아이디, 비밀번호, } \\
\text { 성, 이름, 이메일 주소 } \\
\text { 등을 입력한다. } \\
\text { - 사용자 환경 설정에 대한 } \\
\text { 설정 내용을 입력한다. } \\
\text { - 사용자에 대한 경로 관리에 } \\
\text { 필요한 최소 항목인 } \\
\text { 컨텍스트 레벨, 인스턴스 } \\
\text { 아이디, 경로, 깊이를 } \\
\text { 입력한다. }\end{array}$ & \\
\hline
\end{tabular}

무들 데이터베이스에서 사용자 정보를 관리하는 user 테 이블에는 수많은 필드가 존재한다. 모든 필드를 다 채울 필 요는 없기 때문에, 본 논문에서는 정보이관에 필요한 필수 필드를 제시하고, 나머지 필드들을 정의하는데 필요한 기본 값을 제시함으로써 이관 작업을 간소화 할 수 있도록 하였 다. 이 작업에 필요한 user 테이블의 필드 속성 값을 Table 5 와 같이 변경해야 한다. 
Table 5. Change the default value of User for efficiency

\begin{tabular}{|c|c|c|c|c|}
\hline Table Name: & \multicolumn{4}{|c|}{ user } \\
\hline \multirow{2}{*}{ Field Name } & \multirow{2}{*}{ Type } & \multirow{2}{*}{ Null } & \multicolumn{2}{|c|}{ Default } \\
\cline { 4 - 5 } & & & 변경전 & 변경후 \\
\hline confirmedt & inyint(1) & No & 0 & 1 \\
\hline mnethostid & bigint(10) & No & 0 & 1 \\
\hline country & varchar(2) & No & & KR \\
\hline lang & varchar(30) & No & en_utf8 & ko_utf8 \\
\hline timezone & varchar(100) & No & 99 & 9.0 \\
\hline ajax & tinyint(1) & No & 1 & 0 \\
\hline imagealt & varchar(255) & No & NULL & \\
\hline
\end{tabular}

\section{3) 강좌 데이터 연동 방법}

무들과 기존 학사 시스템 간 강좌 데이터를 연동하기 위 해서 개발자들이 파악해야 하는 무들 데이터베이스 테이블 의 정보는 Table 6 과 같다.

Table 6. Table for Course Management

\begin{tabular}{|c|c|}
\hline 테이블명 & 설명 \\
\hline course & 강좌 관리 \\
\hline course_categories & 범주 관리 \\
\hline block_instance & 강좌에서 사용되는 블록 관리 \\
\hline course_sections & 강좌에서 사용되는 섹션 관리 \\
\hline course_modules & 강좌에서 사용되는 모듈 관리 \\
\hline centext & 무들 시스템에서 범주, 강좌, 블록, \\
& 모듈에 대한 경로 관리 \\
\hline role_assignments & 강좌에서 사용자의 역할 관리 \\
\hline
\end{tabular}

기존 학사 시스템에서 무들로 강좌에 대한 데이터를 이관 할 때 따라야 하는 절차를 Table 7과 같이 수립하였다.

무들 데이터베이스에서 강좌 정보를 관리하는 course 테 이블과 강좌 범주를 관리하는 course_categories 테이블에는 수많은 필드가 존재한다. 강좌 이관에 필요한 필수정보만을 이관하기 위해 필수 필드를 제외한 나머지 필드의 기본 값 을 변경하여 최소의 이관 작업만 할 수 있도록 한다. 기존 학사 시스템에서 무들로 강좌 데이터를 이관 과정 중에 course 테이블과 course_categories 테이블의 속성 값을 Table 8과 같이 변경해야 한다.

\section{3 문제점}

본 논문에서 학사연동에 필요한 테이블들과 이들을 구성 하는 필드를 조작하는 방법을 제시하였으므로, 이를 기반으 로 개발자들은 직접 쿼리(query)를 작성하여 데이터를 연동 할 수 있다. 그러나 퀴리 기반으로 데이터를 연동하면 이관 중 데이터의 일관성을 해칠 위험이 여전히 남아 있다. 또한 본 논문에서 제안한 스키마를 이해하고 제약사항을 참고하 여 쿼리를 작성하더라도 쿼리 작성 결과에 대한 정확성 검 증의 과정이 필요하다. 쿼리 작성 작업을 하지 않고 연동 작업의 일관성을 보장하기 위해 Table 4 , Table 7에 정의한 절차를 자동화한 환경이 필요하다.
Table 7. Procedure for Course data migration

\begin{tabular}{|c|c|c|c|}
\hline 번호 & 활동 & 수행 작업 & 참조 \\
\hline 1 & $\begin{array}{l}\text { 강좌 관련 } \\
\text { 테이블 속성 } \\
\quad \text { 변경 }\end{array}$ & $\begin{array}{l}\text { - 강좌와 관련된 테이블의 } \\
\text { 애트리뷰트 기본값 속성 } \\
\text { 값을 변경한다. }\end{array}$ & Table 8 \\
\hline 2 & $\begin{array}{c}\text { 학사 시스템에서 } \\
\text { 데이터 추출 }\end{array}$ & $\begin{array}{l}\text { · 범주 정보로 필요한 항목인 } \\
\text { 학과명을 가져온다. } \\
\text { - 강좌 정보로 필요한 항목인 } \\
\text { 강좌명과 강좌 단축명을 } \\
\text { 가져온다. } \\
\text { - 강좌를 담당하는 교수자의 } \\
\text { 정보와 강좌를 수강하는 } \\
\text { 학생의 정보인 아이디와 } \\
\text { 이름을 가져온다. }\end{array}$ & \\
\hline 3 & $\begin{array}{c}\text { 무들 강좌 관련 } \\
\text { 테이블에 데이터 } \\
\text { 입력 }\end{array}$ & $\begin{array}{l}\text { ·범주 등록에 필요한 최소 } \\
\text { 항목인 범주명, 상위 범주 } \\
\text { 아이디, 범주 깊이, 범주 } \\
\text { 경로 등을 입력한다. } \\
\text { · 강좌 등록에 필요한 최소 } \\
\text { 항목인 범주 아이디, 강좌 } \\
\text { 전체 이름, 강좌 단축명 } \\
\text { 등을 입력한다. } \\
\text { · 강좌에 사용되는 블록과 } \\
\text { 모듈에 대한 데이터를 } \\
\text { 입력한다. } \\
\text { · 범주, 강좌, 블록, 모듈 등에 } \\
\text { 대한 경로 관리에 필요한 } \\
\text { 컨텍스트 데이터를 } \\
\text { 입력한다. } \\
\text { · 사용자 역할 등록에 필요한 } \\
\text { 최소 항목인 역할 아이디, } \\
\text { 강좌 아이디, 사용자 } \\
\text { 아이디 등을 입력한다. }\end{array}$ & \\
\hline
\end{tabular}

Table 8. Change the default value of Course for efficiency

\begin{tabular}{|c|c|c|c|c|}
\hline \multirow{2}{*}{ Table Name: } & \multicolumn{4}{|c|}{ course_categories } \\
\hline \multirow{2}{*}{ Field Name } & \multirow{2}{*}{ Type } & \multirow{2}{*}{ Null } & \multicolumn{2}{|c|}{ Default } \\
\cline { 4 - 5 } & & 변경전 & 변경후 \\
\hline sortorder & bigint(10) & No & 0 & 999 \\
\hline expirythreshold & bigint(10) & No & 0 & 864000 \\
\hline
\end{tabular}

\begin{tabular}{|c|c|c|c|c|}
\hline Table Name: & \multicolumn{4}{|c|}{ course } \\
\hline \multirow{2}{*}{ Field Name } & \multirow{2}{*}{ Type } & \multirow{2}{*}{ Null } & \multicolumn{2}{|c|}{ Default } \\
\cline { 4 - 5 } & & 변경 전 & 변경후 \\
\hline sortorder & bigint(10) & No & 0 & 100 \\
\hline format & varchar(10) & No & topics & weeks \\
\hline newsitems & mediumint(5) & No & 1 & 5 \\
\hline numsections & mediumint(5) & No & 1 & 16 \\
\hline maxbytes & bigint(10) & No & 0 & $\begin{array}{c}1342177 \\
28\end{array}$ \\
\hline expirythreshold & bigint(10) & No & 0 & 864000 \\
\hline
\end{tabular}




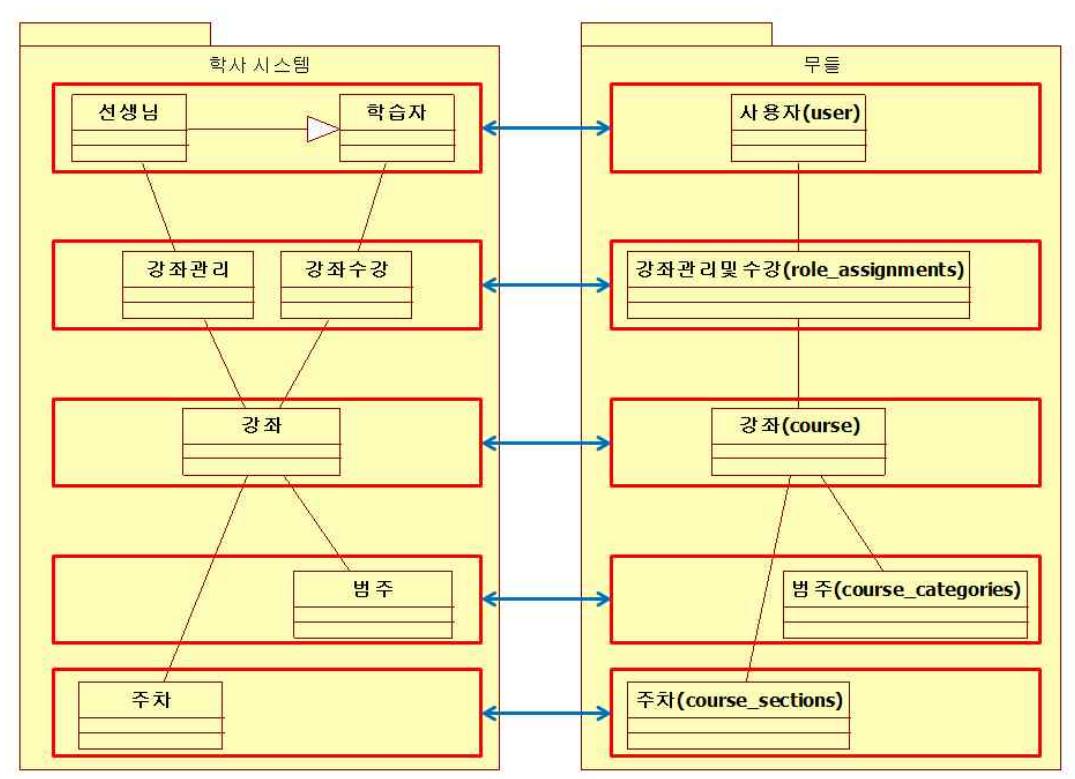

Fig. 1. Conceptual Model

\section{4. 연동 지원 도구 개발}

무들은 모듈 형태로 개발되어 새로 설치 없이 모듈이나 플러그인을 설치하여 사용할 수 있다. 필요한 학습 활동이 나 학습 자원 또는 블록들을 신규 플러그인 형태로 개발하 여 추가함으로써 무들의 기능을 확장할 수 있다. 무들과 학 사 시스템간 쿼리 기반으로 데이터를 직접 연동 과정 중 일 어날 수 있는 문제점을 해결하고자 무들과 학사 시스템간 연동 자동화 환경인 연동 지원 도구를 무들에 설치하여 사 용할 수 있도록 플러그인의 형태 중 블록으로 개발하였다.

\section{1 연동 지원 도구 분석}

\section{1) 개념 모델}

무들을 효율적으로 사용하기 위해 기존 학사 시스템과 무 들을 연동하기 위한 연동 지원 도구의 개념 모델은 Fig. 1 과 같다. 연동 요구사항을 토대로 하여 무들을 사용하기 위 해 필요로 하는 데이터인 사용자, 범주, 강좌, 강의계획, 강 좌 내 사용자 데이터와 기존 학사 시스템간의 데이터를 매 핑했다.

\section{2) 서비스 범위}

연동 지원 도구는 관리자만이 사용 가능하다. 관리자는 연동 지원 도구가 제공하는 연동 지원 기능인 무들과 학사 간 필드 매핑, 사용자 등록, 범주 등록, 강좌 등록, 강좌에 강의계획서 등록, 강좌에 사용자 등록 등이 사용 가능하다. 연동 지원 도구에서 관리자가 사용할 수 있는 기능을 유스 케이스로 모델링하면 다음 Fig. 2와 같다.

\section{2 연동 지원 도구 설계}

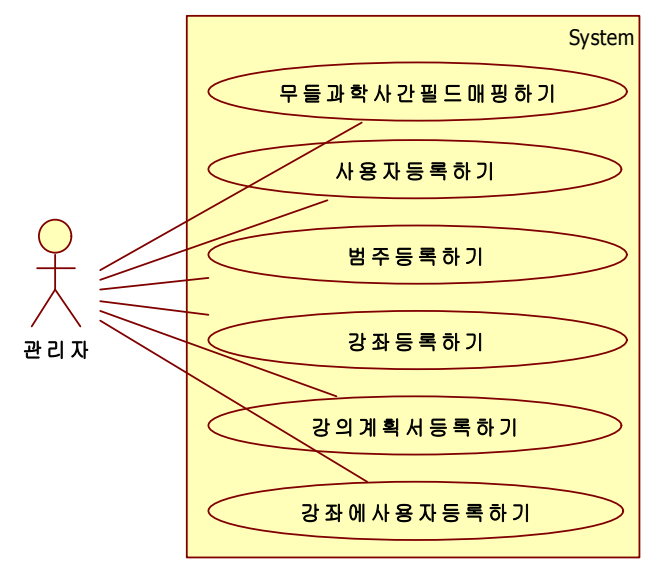

Fig. 2. UseCase Diagram

1) 페이지 설계

학사 시스템과 무들과의 연동 지원을 위한 연동 지원 도 구의 페이지 설계이다. 페이지 설계를 통해 얻은 페이지 목 록은 다음 Table 9 와 같다.

\section{2) 연동 환경 설계}

연동 지원을 하기 위한 연동 지원 도구의 연동 환경 설계 이다. 연동 지원 범위별로 무들과 학사간 필드 매핑, 사용자 등록, 범주 등록, 강좌 등록, 강좌 내 주차별 강의계획 등록, 강좌 내 사용자 역할 등록 등 함수 및 데이터 코드를 개발 하고 각 함수 내에서 다시 필요한 작업을 하기 위해 세부 함수들을 개발한다. 세부 함수로는 사용자 이름을 성과 이 름으로 분리하는 함수, 강좌 개설 년도와 학기, 강좌 코드, 강좌 분반을 합쳐서 강좌의 짧은 이름을 만드는 함수 등 여 러 함수가 있다. 연동 환경 설계를 통해 얻은 결과인 함수 목록은 다음 Table 10과 같다. 
Table 9. Page List

\begin{tabular}{|c|c|}
\hline 페이명 & 설 명 \\
\hline $\mathrm{db} /$ install.php & $\begin{array}{c}\text { 모듈을 설치하는 데 무들과 학사 시스템간 매핑될 필드명이 저장될 } \\
\text { 데이터베이스 테이블을 XMLDB로 작성 }\end{array}$ \\
\hline block_haksa.php & 학사 블록의 기본 클래스 \\
\hline haksa_form.php & 학사 블록이 출력되는 정보 및 형식을 작성 \\
\hline tabs.php & 연동 지원 범위별 메뉴를 작성 \\
\hline map.php & 무들과 학사 시스템간 매핑될 필드명을 입력하는 페이지 \\
\hline user.php & 상자 등록 페이지 \\
\hline category.php & 범주 등록 페이지 \\
\hline course.php & 강좌 등록 페이지 \\
\hline week.php & 강좌 내 주차별 강의계획 등록 페이지 \\
\hline assign.php & 강좌 내 사용자 역할 등록 페이지 \\
\hline lib.php & 연동 지원에 필요한 함수를 라이브러리로 작성 \\
\hline
\end{tabular}

Table 10. Function list of migrataion environment

\begin{tabular}{|c|c|}
\hline 데이터 코드명 & 설 명 \\
\hline block_haksa_parseXLS() & 엑셀 파일을 파싱해서 배열로 반환 \\
\hline block_haksa_add_teachers() & 교수자를 등록 \\
\hline block_haksa_add_students() & 학습자를 등록 \\
\hline block_haksa_add_users() & 교수자와 학습자의 정보를 받아 사용자를 등록 \\
\hline block_haksa_get_role() & 사이트 권한을 반환 \\
\hline block_haksa_split_fullname() & 이름을 성과 이름으로 분리 \\
\hline block_haksa_create_categories() & 범주를 생성 \\
\hline block_haksa_create_category() & 범주를 DB에 등록 \\
\hline block_haksa_compare_category() & 범주를 정렬할 때 비교 \\
\hline block_haksa_save_category_info() & 강좌 등록 시 범주 정보를 가져오기 위해 범주를 $\mathrm{DB}$ 에 저장 \\
\hline block_haksa_create_courses() & 강좌를 생성 \\
\hline block_haksa_course_syllabus() & 강좌에 강의계획 정보를 입력 \\
\hline block_haksa_make_course_shortname() & 강좌의 짧은 이름(shortname)을 생성 \\
\hline block_haksa_assign_teachers() & 강좌에 교수자를 등록 \\
\hline block_haksa_assign_students() & 강좌에 학습자를 등록 \\
\hline block_haksa_save_mapping_info() & 무들과 학사 시스템간 매핑될 필드명을 DB에 저장 \\
\hline
\end{tabular}

\section{3 연동 지원 도구 구현 결과}

데이터간 일관성을 해치지 않고 학교별 무들 활용 과정을 효율적으로 지원하는 도구를 구현하였다. 무들과 기존 학사 시스템간 데이터 연동을 위해 필요한 작업별로 자동화 환경 이 제공하는 기능은 다음과 같다.

(1) 무들과 학사간 필드 매핑: 이관 대상별로 무들이 정의한 데이터베이스 항목과 학사 시스템이 정의한 항목을 Fig. 3 과 같이 매핑한다.

(2) 사용자 등록: 스키마 매핑 정보를 바탕으로 학사 시스템 으로부터 추출한 사용자 데이터를 무들 시스템에 자동으
로 등록된다.

(3) 범주 등록: 학사 시스템으로부터 추출한 학과, 학부, 전공 및 이수구분 데이터를 무들 시스템에 자동으로 등록된다.

(4) 강좌 등록: 학사 시스템으로부터 추출한 강좌 데이터를 Fig. 4와 같이 무들 시스템에 자동으로 등록된다.

(5) 강의계획서 등록: 학사 시스템으로부터 추출한 강의계획 데이터를 무들 시스템에 자동으로 등록된다.

(6) 강좌에 사용자 등록: 학사 시스템으로부터 추출한 강좌 담당 및 강좌수강 데이터를 무들 시스템에 자동으로 등록 된다. 


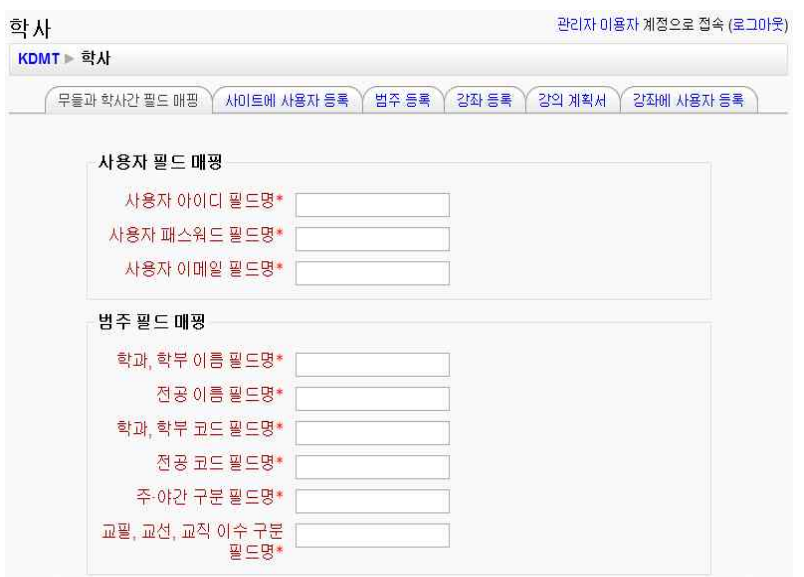

Fig. 3. Screenshot for mapping between Moodle and Administration system

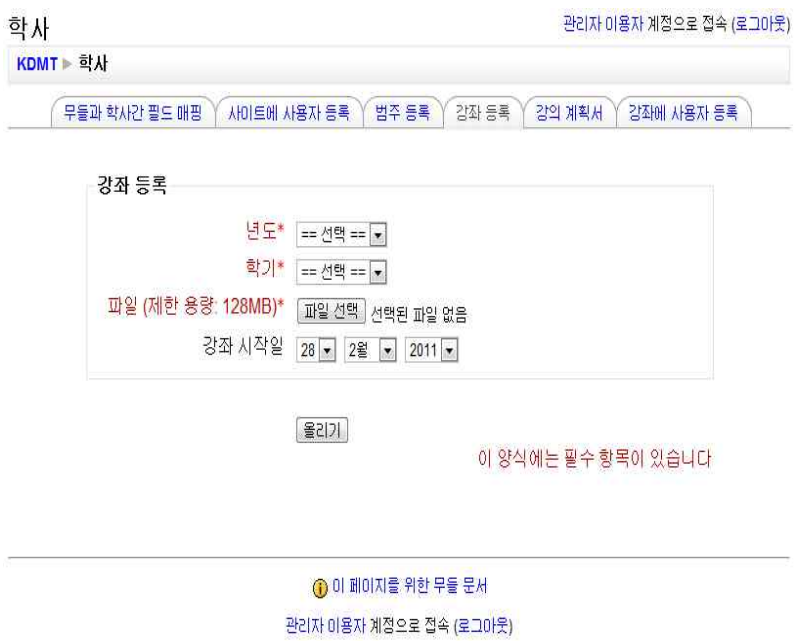

Fig. 4. Screenshot of Course registration

\section{5. 적용 사례}

본 논문에서 제안한 무들 연동 지원 도구의 활용도를 검 증하기 위하여 관동대학교에 무들을 적용하는 과정에 적용 하였다. 기존 학사 시스템으로 부터의 사용자와 강좌 정보 를 빠르고 정확하게 무들로 이관함으로써 관동대학교에 필 요한 무들 운영 환경을 쉽게 구축할 수 있었다.

\section{1 연동 지원 도구 적용 범위}

무들과 학사 시스템간 연동 지원 도구를 관동대학교 대상 으로 무들과 학사간 필드 매핑, 사용자 등록, 범주 등록, 강 좌 등록, 주차별 강의 계획 등록, 강좌별 사용자 등록 등을 할 수 있도록 적용하였다.

1) 무들과 학사 시스템간 필드 매핑한 화면

무들과 기존 학사 시스템간 연동 지원 도구를 적용하여 기존 학사 시스템에서 추출한 데이터를 무들에 등록하기 위 해 필드 매핑을 한다. 무들과 학사 시스템간 필드 매핑은

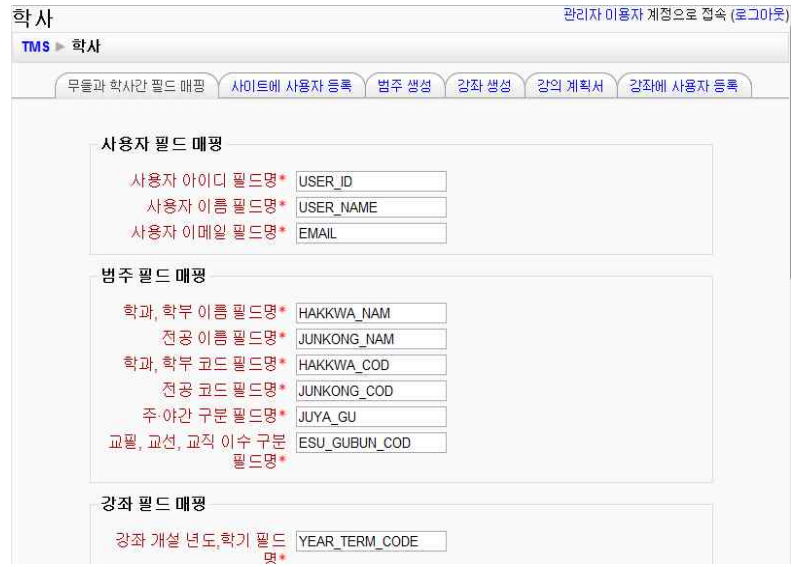

Fig. 5. Result of the mapping between Moodle and Administration system

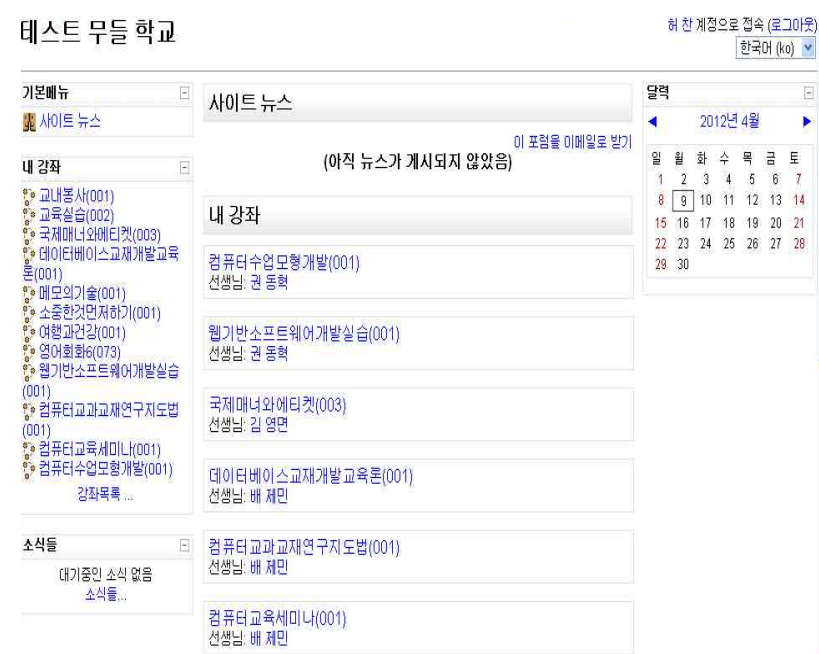

Fig. 6. Screenshot of Course registration

Fig. 5 와 같이 기존 학사 시스템에서 추출한 데이터의 스키 마를 필드 매핑 란에 입력한다.

\section{2 연동 지원 도구 적용 결과}

무들과 학사 시스템간 연동을 위한 사용자 관리와 강좌 관리를 만족하는 연동 지원 도구를 적용한 결과로 사용자가 로그인을 하면 로그인한 사용자가 수강하는 강좌의 목록들 을 확인할 수가 있다. 연동 지원 도구를 적용한 결과의 화 면인 강좌 수강 목록 화면은 Fig. 6과 같다.

\section{3 연동 지원 도구 활용 방법}

무들과 학사 시스템간 연동을 위해 연동 지원 도구에 대 한 활용 방법은 무들이 설치된 디렉터리 중 하위 디렉터리 인 'blocks' 디렉터리 아래에 연동 지원 도구를 설치하여 활 용이 가능하다. 설치를 마친 후, 다음 Table 11 과 같이 학사 시스템의 데이터베이스 구조를 분석하고, 무들과 연동에 필 요한 필수 데이터들을 엑셀 파일로 추출을 하고, 무들에 등 록하여 활용이 가능하다. 
Table 11. Procedure for deployment

\begin{tabular}{|c|c|c|}
\hline 단계 & 활동 & 작업 \\
\hline \multirow{5}{*}{ 분석 } & \multirow{2}{*}{$\begin{array}{l}\text { 무들 } \\
\text { 분석 }\end{array}$} & 테이블 목록 파악 \\
\hline & & 필수 애트리뷰트 분석 \\
\hline & \multirow{2}{*}{$\begin{array}{c}\text { 학사 } \\
\text { 시스템 } \\
\text { 분석 }\end{array}$} & 테이블 목록 파악 \\
\hline & & 필수 애트리뷰트 분석 \\
\hline & $\begin{array}{l}\text { 갭 } \\
\text { 분석 }\end{array}$ & $\begin{array}{c}\text { 무들과 학사 시스템 사이의 } \mathrm{DB} \text { 스키마 } \\
\text { 타입의 차이 파악 }\end{array}$ \\
\hline \multirow{3}{*}{ 적용 } & \multirow{3}{*}{ 연동 } & $\begin{array}{c}\text { 무들과 연동하기 위한 학사 시스템의 필수 } \\
\text { 정보를 추출 }\end{array}$ \\
\hline & & 무들과 연동하기 위해 스키마 매핑 \\
\hline & & $\begin{array}{c}\text { 학사 시스템으로부터 추출한 필수 정보를 } \\
\text { 무들에 등록 }\end{array}$ \\
\hline
\end{tabular}

\section{6. 결 론}

이러닝의 보급과 유러닝의 확대로 인해 학교에서는 LMS 의 도입이 증가되고 있다. 상용 $\mathrm{LMS}$ 는 고가이며 도입 및 수정에 어려움이 따른다. 이에 비해 공개소프트웨어 LMS는 도입 비용을 절감할 수 있으며 검증된 최신의 개념들을 반 영할 수 있고, 소스가 공개되어 있기에 수정도 용이하다. 공 개소프트웨어 $\mathrm{LMS}$ 를 도입하기 위해서는 각 학교의 특성과 교과 운영 방식 및 학습자의 특성에 맞도록 커스터마이징이 필요하다.

본 연구에서는 공개소프트웨어 $\mathrm{LMS}$ 인 무들을 도입함에 있어 공통적인 요구사항으로 무들과 학사 시스템간 연동이 필요함을 식별하였고, 연동에 필요한 요구사항을 식별하였 다. 요구사항 중 사용자 관리와 강좌 관리를 하기 위한 데 이터 연동에는 사용자 등록, 범주 등록, 강좌 등록, 강좌 내 강의계획 등록, 강좌 내 사용자 등록 등의 세부 작업을 식 별하였다. 효과적으로 무들을 사용할 수 있도록 식별한 요 구사항을 바탕으로 무들 연동 지원 도구를 구현하였다.

플러그인으로 개발된 연동 지원 환경은 데이터베이스를 직접적으로 수정하여 연동할 경우에 일어나는 문제점인 데 이터간 일관성을 유지할 수 있다. 또한, 데이터베이스에 직 접 쿼리를 입력하지 않아도 된다는 점에서 기존 시스템과의 연동에 편이성을 제공한다.

향후, 본 연구의 성과를 기초로 하여 무들 커스터마이제 이션에 대한 연구 방향은 강좌 범주를 등록할 때 각 학교에 따라 범주 구분 방법이 다르므로 가변성을 적용하여 유연하 게 플러그인을 개발하는 연구가 필요하다.

이러한 무들 활용에 대한 연구 활동이 더 진행된다면 각 기관에서 무들에 대한 활용률이 증가 될 수 있을 것이다.

\section{참 고 문 헌}

[1] MoonJoo Kwon, An Exploratory Study into Open Source
Software Adoption and Resistance Factors”, Ph.D Thesis of SungKyungKwan University, 2009.

[2] JongHyun Lee, "Study on the revitalization of Open Source Software in Pubiic sector", Master Thesis of YeonSei University, 2007.

[3] Joon Lee, "LCMS(Learning Content Management System) based e-Learning Development and Application", Korean Association for Educational informational and Media, Vol.8, No.2, pp.93-113, 2002.

[4] YoonSoo Kim, "On-line learning management system based on GPL", Master Thesis of JeonJu University, 2008.

[5] Hyejin Park "Design and Implementation of 'Information' Subject study method by Moodle", Master Degree of KyungGi University, 2010.

[6] WoonHee Baek, "The Current Development State and Operation Cases Analysis of Open Source Learning Management System", Master Degree of KaeMyung University, 2011.

[7] MeeYeon Kim, "Comparative Analysis on the Instructional Function of Open Source Learning Management System", Master Degree of Ajou University, 2009.

[8] Moodle, http://moodle.org

[9] JooHyun Song, "A study on value of the open source softwares and their economic influence", Master Degree of YeonSei University, 2007.

[10] http://www.doopedia.co.kr/doopedia/

[11] HyungMee Na, "A Study on Model of Learner Oriented u-LMS”, Ph.D Degree of SoongSil University, 2008.

[12] Yoon Seon Nam, "Implementation of LMS Interconnection Model for Inter-University e-learning Management", Ph.D Degree of KangWon University, 2009.

[13] JaeCheon Park, et. al., "A system for elementary students' writing education applied in open source LMS", in Proceeding of conference of Korea Soceity for Internet Information, Vol.9, No.1, pp.427-430, 2008.

[14] R.Calvo, R.Ellis, D.Peters, "Internationalisation and E-learning Systems; .LRN Case Studies”, Online EDUCA2005, 2005.

[15] Won Kyung Choi, "A Study on Cooperative and Self-regulated English Learning Experience with Moodle", New English Language and Literature Association for Korea, Vol.42, pp.247-268, 2009.

[16] YoungTae Baek, SeHoon Lee, "Development of e-Learning System Based on Open Source Software", Journal of Korea Contents Association, Vol.5, No.1, pp.9-17, 2005.

[17] Sin Woon Kim, "Design and Implementation of Program for Expanded Module of Open-source Moodle LMS", Master Degree of ChonBuk University, 2010. 


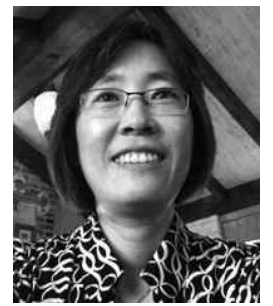

\section{김 정 아}

e-mail : clara@kd.ac.kr

1988년 중앙대학교 전자계산학과(학사)

1990년 중앙대학교 컴퓨터공학과

(공학석사)

1994년 중앙대학교 컴퓨터공학과 (공학박사)

1996년 현 재 관동대학교 컴퓨터교육과 교수

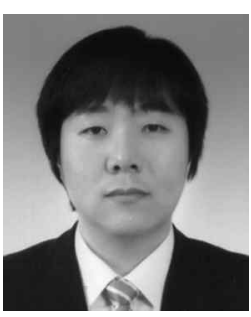

관심분야: 객체 지향 방법론, 컴포넌트 기반 방법론, 제품라인 공학, 소프트웨어 프로세스 개선
박 선 균

e-mail : refmeju@nate.com 2010년 관동대학교 컴퓨터교육과(학사) 2012년 관동대학교 경영정보학과 (경영학석사)

2012년 현 재 인천과학고등학교 교사 관심분야: 컴퓨터 교육, 모바일 프로그래밍 개발, 웹 프로그래밍 개발 